\title{
Jardins botânicos como espaços de descoberta: o trabalho de campo no ensino de Geografia
}

\section{Editor}

Maria Inês Côrte Vitoria PUCRS, RS, Brasil

\section{Equipe Editorial}

Pricila Kohls dos Santos PUCRS, RS, Brasil

Marcelo Oliveira da Silva PUCRS, RS, Brasil

Carla Spagnolo PUCRS, RS, Brasil Rosa Maria Rigo PUCRS, RS, Brasil

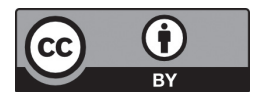

A matéria publicada neste periódico é licenciada sob forma de uma Licença Creative Commons - Atribuição 4.0 Internacional. http://creativecommons.org/licenses/by/4.0/
RESUMO: É possível construir conhecimento em jardins botânicos, através da Geografia, ou não? Um jardim botânico é elemento do espaço geográfico, de modo que se apresenta como um conjunto solidário, contraditório e inseparável de objetos e ações. A compreensão do todo depende das partes, e estas da totalidade. Ciente de tal postulado, o artigo apresenta um conjunto de atividades pedagógicas, elaboradas com o amparo das teorias do Ensino de Geografia e da Pedagogia Social Crítica, mediadas pela Epistemologia Genética. O artigo aponta a necessidade da construção, na escola, de um pensamento reflexivo, voltado à cidadania, compreendendo os alunos enquanto sujeitos históricos no processo de mudança da sociedade. O trabalho de campo é uma aproximação com a realidade, demonstrando que tudo está ligado a tudo, e é através do que o aluno tem de disponível que o ensino e a aprendizagem têm significado e maior possibilidade de serem construídos com efetividade. Nesse sentido, o trabalho de campo se posiciona enquanto elemento de desafio sobre os sujeitos, pressionando-os a agir no espaço geográfico de maneira competente.

Palavras-chave: Jardins botânicos. Educação ao ar livre. Ensino de Geografia.

ABSTRACT: Fieldwork represents a vital instrument for understanding our world through direct experience, for gathering data about it, and as a fundamental method for fomenting geographical education. The investigation of the relationship between Geography teaching and public spaces by fieldworks is the issue of this article. Fieldworks allow an approach to reality showing that everything is connected to everything. Moreover, constructing knowledge in botanical garden through Geography is possible or not? From that, we propose a set of pedagogical activities supported by Geography teaching theories and Critical Pedagogy related to the Genetic Epistemology. This article indicates the necessity of constructing a reflexive thought in the school oriented to

\footnotetext{
a Mestre em Geografia pela UFRGS. Licenciado em Geografia. Professor do Colégio Tiradentes de Porto Alegre (CTBM-PA) e do Colégio Marista Assunção. E-mail: <brunonunes.86@hotmail.com>.

b Doutor em Comunicação Social pela PUCRS. Mestre em Educação pela UFRGS. Professor da Faculdade de Educação da UFRGS e do Instituto de Filosofia e Ciências Humanas da PUCRS. Professor do Programa de Pós-Graduação em Geografia da UFRGS. E-mail: <castroge@ig.com.br>.
} 
citizenship considering students as subject in changing society processes. Fieldwork allow an approach to reality showing that everything is connected to everything. Exploring student previous knowledge is the major source of meaningful teaching and learning possibilities.

Keywords: Botanic garden. Outdoor learning. Geography teaching.

D efinitivamente, da educação um dos poucos elementos dos quais podemos ter certeza é de que ela não permite soluções fáceis. Ensinar, efetivamente, é um processo complexo de múltiplas verdades. Não é o caso de definir o que é certo ou errado, tradicional ou inovador, mas de poder refletir quais instrumentos são capazes de auxiliar na construção do conhecimento na escola. O cotidiano docente olha para o futuro, mas não negligencia o passado. Utiliza a experiência, porém age e planeja estrategicamente frente às vicissitudes e surpresas que virão na caminhada. Nesse contexto, ser professor é, apropriando-se das poéticas palavras de Fernando Sabino, "Fazer da interrupção um caminho novo. Fazer da queda um passo de dança, do medo uma escada, do sono uma ponte, da procura um encontro" (SABINO, 2008, p. 161).

Para o educador de Geografia, o confronto entre o que é novo e o que é considerado antigo é particularmente diferente. Historicamente, a Geografia escolar se desenvolveu à sombra de rótulos. O estudante que frequentou a Escola Básica tem grandes chances de ter reclamado de como esse componente escolar era chato, desinteressante e, amiúde, inútil. Chato e desinteressante no sentido de não possuir emoção, tensão, vida. Inútil porque, entre outras coisas, a Geografia na escola ficou famosa por ser uma ciência mnemônica, um momento de se decorar capitais, países, relevos de lugares distantes e índices populacionais defasados.

A tensão do ensino de Geografia na contemporaneidade é grande. Por um lado, não é recomendável romper com todas as heranças históricas do seu ensinar. Por outro, é ponto premente destacar que a escola atual não pode mais trabalhar apenas a descrição dos fenômenos e os conteúdos como fins em si mesmos, deixando de lado os processos de construção da ciência e da própria sociedade como um todo. Se o professor de Geografia aposta somente na primeira alternativa, corre o risco de ser "engolido" pelos arredores escolares, constituídos por novas tecnologias e múltiplas realidades, que são inclusive contraditórias. No entanto, se esse mesmo professor rompe com a tradição materializada e aposta na suposta "inovação" pedagógica, provavelmente encontrará freios postos pela instituição escola e pelos próprios alunos, que carregam e reproduzem uma herança escolar que Freire (2011b) já caracterizou como uma educação bancária, na qual prevalece a avaliação classificatória e descritiva, e a monológica, caracterizada por um único saber, uma só verdade. 
É necessário que o educador aja de maneira complexa. Religue os saberes. Ancore-se na incerteza. Para Morin (2006), trabalhar com a complexidade, nos processos de ensino e aprendizagem, é ter a consciência de que o mundo é feito por múltiplas verdades, relações sociais retroativas, dúvidas permanentes. Antes da corrida irrefreável por respostas, devemos aprender a fazer perguntas.

Construindo perguntas, aprendemos a pensar. Nessa esfera, o presente artigo é, antes de tudo, uma pergunta. Como construir instrumentos que possibilitem o ensino e a aprendizagem da Geografia na contemporaneidade? Foi pensando em respostas, que igualmente são provisórias, que iremos apresentar aqui possibilidades de se estimular o ato de pensar, na escola. Como pano de fundo, temos o trabalho de campo no ensino de Geografia. É uma das maneiras de mostrar para os estudantes que a escola não se encerra nos seus muros e que o conhecimento transgride suas fronteiras físicas, inclusive derrubando-as.

Pensando em aproximar o ensino da realidade e dialogar com os arredores escolares, elencamos os jardins botânicos, espaços privilegiados nas tramas urdidas das grandes metrópoles brasileiras, como espaços de análise que instiguem, antes de qualquer coisa, o diálogo com a sociedade e o ato de reflexão. Dessa forma, o texto contextualiza o ensinar Geografia na contemporaneidade com as possibilidades de construção do conhecimento, sugerindo, portanto, um conjunto de didáticas que podem auxiliar nos processos de ensino e aprendizagem nas aulas de Geografia.

\section{Ensinar Geografia na contemporaneidade é... 0 trabalho de campo como instrumento de compreensão do mundo}

Na vastidão de saberes dos quais o mundo é formado, conhecemos muito pouco. Em um processo constante de vir a ser, qual é o sentido existe em ver o mundo pela certeza, ancorado nas verdades permanentes? Não parecem existir respostas definitivas, apenas hipóteses e estas, igualmente, são provisórias. "O mundo não é. O mundo está sendo." (FREIRE, 2011a, p. 74). Quanto mudou no mundo na última década, no último ano, no último mês? Na última semana? O movimento define-se por encontrar ferramentas para as dúvidas: "Me movo como educador porque, primeiro, me movo como gente" (FREIRE, 2011a, p. 92).

Com efeito, buscamos inserir-nos numa realidade de aproximação do currículo com o mundo empírico através do trabalho de campo, uma tendência que diversas correntes pedagógicas, sobretudo no continente europeu e asiático, estão buscando compreender e realizar (VESENTINI, 2004; BEAMES; ROSS; 2010). Em realidade, parece que uma das tarefas da educação geográfica é buscar que os estudantes consigam compreender o seu mundo de entorno, de maneira consciente e solidária. 
É fato que ainda se atribui à Geografia uma função cartesiana e descritiva dos inúmeros saberes que produzem as relações espaciais (CASTROGIOVANNI, 2007). O reducionismo de causa e efeito na Geografia escolar, embora ainda esteja presente na escola, parece que já encontra uma resistência dos educadores que, cientes da importância da Geografia na formação de cidadãos conscientes da realidade, refletem sobre as suas práticas. O que é uma necessidade: "Trabalhar com a noção de causa e efeito é trabalhar como o que se vê; e trabalhar com a noção de contexto é trabalhar também com o que não se vê e frequentemente é ainda mais importante que o visível" (SANTOS, 2012, p. 264). A forma e a aparência, que regem as leis causais e de efeito, são substituídas pela explicação que investiga o que está por detrás dos fenômenos, buscando a resposta para o que parece estar invisível.

O postulado atual no ensino de Geografia é o de aproximação do que os sujeitos alunos têm de disponível nos seus movimentos perante o espaço geográfico. De acordo com Costella (2008), é na teorização das vivências do aluno que se abre uma porta de entrada para o sujeito adentrar em patamares de complexidade superiores no entendimento das relações de ordem planetárias. Para a autora, o conhecimento anterior do sujeito, interligado a processos de saberes construídos ao longo das vivências, é de suma importância na elaboração de futuros conhecimentos, visto que essa nova construção "[...] está atrelada a atos reflexivos sobre uma composição antiga, já construída" (COSTELLA, 2008, p. 25).

Castellar et al. (2011, p. 254) escreve com outras palavras, mas expressa a mesma opinião: “A partir do momento em que pensamos como o vivido pode ser importante para desvendar as contradições existentes no cotidiano, os alunos param para refletir sobre sua vida". É na reflexão das conceituações iniciais que concernem às experiências que o sujeito já possui que é possível ultrapassar o senso comum e avançar no entendimento da complexidade dos constructos conceituais.

Uma maneira de aproximação com o contexto dos sujeitos alunos pode ser a partir do bairro, das redes sociais, das informações que a mídia apresenta que são passíveis de serem compreendidas e reordenadas. A escola, como um espaço de realização de leitura do mundo e que fornece instrumentos para a reflexão articulada sobre a vida constrói significado quando leva em conta "[...] que os conteúdos em si são mais do que simples informações a serem aprendidas, eles devem significar a possibilidade de se aprender a pensar" (CALLAI, 2009, p. 89). A aprendizagem do pensamento, através da análise geográfica, deve começar do que existe de disponível, já que a realidade contígua não raramente deixa de ser compreendida e confrontada. Nessa esfera, para Kaercher (2003), o educador que consegue que os alunos percebam “[...] coisas até então imperceptíveis, então estará estimulando-os a ler o mundo com outros olhos" (KAERCHER, 2003, p. 79).

Quando estamos defendendo a necessidade de trabalharmos a Geografia tomando como ponto de partida os lugares do aluno, estamos indo ao encontro de valorizar o que Piaget (2008) chama de conteúdos experimentais. 
Os conteúdos experimentais - embora tenham validade por representarem o contato imediato que o sujeito exerce em interação com o objeto - precisam estar unidos de maneira lógica e tal processo é alcançado a partir do que o autor denomina como organização: "É adaptando-se às coisas que o pensamento se organiza e é organizando-se que estrutura as coisas" (PIAGET, 2008, p. 19). Entretanto, a organização é dependente íntima dos processos de assimilação e acomodação, estes sendo, igualmente, inseparáveis.

Piaget (2008) descreve a assimilação como a atividade egocêntrica do sujeito, que exerce atos de julgamento sobre o meio exterior, sendo que o ato de julgar é relacionado aos conhecimentos prévios que o sujeito possui: "Não há dúvida de que um ato inteligente só é determinado pela experiência anterior na medida em que a ela recorre" (PIAGET, 1983, p. 73). Nesse sentido, escreve Piaget (1983) que o ato presente de inteligência tem relação de mutualidade com a experiência anterior, pautada por uma ação que não acontece em sentido único do passado para o presente. A assimilação confere ou não uma significação às coisas, visto que representa a ação do sujeito sobre o objeto. Como resultado, “[...] para que o estímulo desencadeie certa resposta, é necessário que o sujeito e seu organismo sejam capazes de a fornecer, daí a questão prévia ser quanto a esta capacidade [...]" (PIAGET, 1978, p. 33). Não existe, para a Epistemologia Genética, conhecimento que parta do vazio, pois tudo está ligado a tudo, de modo que se deve ter consciência de que o principal não é o estímulo - aqui os conceitos de Geografia - "[...] mas a sensibilidade ao estímulo e este depende naturalmente da capacidade de dar uma resposta" (PIAGET, 1978, p. 33). Parte-se, então, do que os sujeitos já conhecem, e isso comporta um universo de possibilidades. Dessa forma, o processo de acomodação é a experiência imposta pelo meio exterior (PIAGET, 2008). Ela permite que o sujeito se situe num emaranhado de perspectivas que assegura a objetividade e reduz a influência egocêntrica do pensamento individual: "A acomodação é fonte de mudança" (MAURICE-NAVILLE; MONTANGERO, 1998, p. 99). Esses dois processos são correlativos e caminham lado a lado na construção do conhecimento, de modo que se completam de maneira recíproca: "[...] o conceito de acomodação não se concebe sem o da assimilação que constitui o fato primeiro" (MAURICE-NAVILLE, MONTANGERO, 1998, p. 100).

Pelo prisma do ensino de Geografia, as temáticas têm sentido para os estudantes quando eles já tiveram contato com aquelas teorizações, através da experiência real, que é imposta pelas necessidades individuais. Se a Geografia escolar não fornecer instrumentos para dar conta da vida do sujeito aluno, dificilmente terá alguma validade que consiga, satisfatoriamente, possibilitar a construção do conhecimento geográfico. Nessa direção, o aluno aprende Geografia quando é competente em assimilar os conceitos estruturantes da disciplina e tal prática é "refém" da bagagem de conhecimentos que ele traz das interações anteriores com o meio no qual está inserido. Justamente por isso, "A educação não á uma fórmula de escola, mas sim uma obra de vida" (FREINET, 1991, p. 7). É a teorização do espaço vivido que tem significado para os alunos e, com efeito, desequilibra-os. 
No que se refere ao desequilíbrio, trata-se de um ato de perturbação cognitiva no qual o sujeito sente necessidade de dar conta daquele conflito exercido pelo meio exterior para dar sentido a sua existência e "[...] com efeito, a acomodação só é possível em função da assimilação, visto que a própria constituição dos esquemas chamados a acomodar-se é devida ao processo desequilibrador" (PIAGET, 2008, p. 382). Para Franco (1998), o desequilíbrio é um fenômeno de composição dialética, pois para que aconteça a abstração o sujeito necessita "[...] de algo que o negue, que crie a necessidade de transformação" (FRANCO, 1998, p. 15). Em linha semelhante de raciocínio, assevera Piaget (1983, p. 48) que "Toda nova aquisição modifica as noções anteriores ou ameaça ensejar a contradição". Dito de outro modo, a interatividade entre o sujeito e o objeto e, aqui, entre o aluno e a Geografia, é uma relação estabelecida entre dois polos que não necessariamente são iguais - podem inclusive negar-se, mas que, ao fim e ao cabo, engendram uma realidade nova.

Como escreveu Freinet (1991, p. 21), "a vida prepara-se pela vida". A consciência de que devemos apontar como ponto de partida a teorização da realidade, paradoxal que é, está no cerne de práticas pedagógicas que tenham alguma validade e posicionem a escola como instituição indispensável ao complexo mundo do qual fazemos parte. Adentrar com competência crítica e consciência social na sociedade multidimensional produzida pelo processo de Globalização é uma das responsabilidades que legitimam a existência da ciência Geografia no currículo da Escola Básica. Concordamos com Castrogiovanni (2011), no que se refere ao pensamento Geográfico como instigador da dúvida acerca de um mundo que vislumbra uma nova realidade, igualitária e, sobretudo, ética: "[...] um espaço mais adequado a trocas, à instrumentalização de hábitos e atitudes. Espaço que favoreça a reunião e a criação" (CASTROGIOVANNI, 2011, p. 66).

Entretanto, a prática do estudo da realidade além da materialidade da escola parece evocar não apenas método, mas estratégia. Afirmamos isso quando nos referimos à reflexão do que se faz necessário para que o trabalho de campo torne-se um veículo pedagógico viável, que proporcione uma nova leitura da realidade. Se a Geografia escolar insistir na prática fragmentada da vida, que reduz o mundo a parcelas que não dialogam entre si, a atividade tem o seu significado prejudicado. Facilmente um trabalho de campo parece transformar-se em apenas um campo sem trabalho, e é esse alerta que Pontuschka (2004) realiza, no sentido da construção de um trabalho que leve "[...] aluno e professor a um compromisso com a sociedade e suas transformações, possibilitando o encontro entre sujeitos diferentes que crescem individualmente, que podem trocar, ensinar e aprender" (PONTUSCHKA, 2004, p. 256).

Para a autora, em outra obra (PONTUSCHKA et al., 2009), o trabalho de campo que não fragmenta o mundo é um instrumento eficaz pelo qual podemos apontar os conteúdos da Geografia não como fins em si mesmos, mas de maneira que eles consigam ser meios pelos quais os estudantes interajam com a realidade e construam uma leitura articulada, coesa e crítica sobre o espaço geográfico. 
Todavia, até que ponto emerge a posição do docente na elaboração de um trabalho ao ar livre? Para Castrogiovanni (2011), a escola deve buscar caminhos facilitadores para a construção do conhecimento. Pontuschka et al. (2009) são de mesmo pensamento: cabe à escola ensinar o aluno a ler o mundo, o que "[...] implica um processo permanente de decodificação de mensagens, de articulação/contextualização das informações" (PONTUSCHKA et al., 2009, p. 263). A reflexão acerca da realidade, seja ela local, regional ou nacional, demanda técnica, visto que emana uma miríade de competências que precisam ser elaboradas. Nas palavras de Schaffer (2003), a orientação docente através de um roteiro deve acontecer, entretanto essa proposta necessita " [...] ultrapassar a etapa do ver/registrar e programada para que o grupo avance no sentido de inferir, isto é, levantar suposições, hipóteses, a partir do que é observado; investigar [...]" (SCHAFFER, 2003, p. 92).

Com Cavalcanti (2011), aprendemos que da escola não devemos esperar soluções fáceis para os seus problemas. Para a autora, "[...] a diversidade e a complexidade no ato de ensinar são muito grandes, como de resto o são as atividades profissionais que requisitam a relação direta com as pessoas" (CAVALCANTI, 2011, p. 79). A construção de um trabalho de campo é também subjetiva, na esteira de incertezas, no sentido de que eles são imprevisíveis, e não podem com certeza antecipar o que vai interessar os alunos ou não, e envolvem riscos da realidade além da escola (BEAMES; ROSS, 2010). Portanto, em um mundo que comporta inúmeras verdades sobre o mesmo prisma, optamos aqui pela construção do conhecimento instrumentalizado pela ciência da Geografia e essa, acreditamos, é perpassada por uma série de operações construídas pelos seus conceitos próprios. O roteiro estruturado, como proposta para construir um trabalho de campo, é uma das maneiras de operacionalizar o conhecimento.

\section{Nos jardins botânicos, muito além deles...}

Entender jardins botânicos como pontos constituintes da sociedade pode alcançar patamares proveitosos de ensino e aprendizagem. Tais espaços abarcam uma potencialidade subaproveitada, que pode despertar sentimentos não apenas topofílicos, mas também exortando a conscientização de um mundo paradoxal.

O caminho, contudo, transcorre além de explicar os jardins botânicos apenas por eles mesmos. A descrição linear dos seus elementos não abarca um estudo do meio significativo. Como Santos (2009) escreveu, não é possível que se descreva objetos sem explicá-los: o alicerce da descrição é a intenção de explicar. Negar a compreensão dos processos desencadeia "[...] peças isoladas, distanciando-nos do ideal de coerência próprio a um dado ramo do saber e do objeto de pertinência indispensável" (SANTOS, 2009, p. 19).

Propostas pedagógicas nos jardins botânicos são bem-vindas e justificáveis. Fundamentalmente porque, nas palavras de Segawa (1996, p. 223), “A natureza, a paisagem, o jardim público, nada significam por si. São os humanos 
que atribuem significados que vão qualificar as imagens, os objetos". No mesmo contexto, para Peixoto e GuedesBruni (2010), os jardins botânicos são áreas de conservação de intensa beleza, com capacidade ímpar de sensibilizar a sociedade em torno de uma agenda verde: "Os laços emocionais e interesses cognitivos proporcionados por atividades de lazer junto à natureza fazem aumentar o comportamento pró-ambiente" (PEIXOTO; GUEDES-BRUNI, 2010, p. 18). A construção de atividades educacionais, como resultado, desperta o recrudescimento do encanto do sujeito pela natureza, proporcionando uma virada de paradigma social, que problematize os pilares econômicos, políticos e culturais da sociedade, transformando o comportamento consciente das pessoas.

Os jardins botânicos abarcam especificidades que os tornam importantes aos sujeitos conscientes da valorização da natureza no século XXI. Contudo, Segawa (1996, p. 223) alerta: “A natureza, a paisagem, os jardins são entidades demasiadamente complexas, estimulantes e dispersivas para serem pronta e diretamente assimiladas pela sensibilidade humana". É necessário que saibamos interpretá-los e, notadamente, contextualizá-los com escalas de maiores densidades espaço-temporais.

Integrando técnicas de conservação e de plantas fora do seu ambiente com a preservação de plantas endêmicas para a manutenção dos seus ciclos biológicos e processos evolutivos, os jardins botânicos atuam hoje na manutenção da biodiversidade e como agentes sensibilizadores do público com relação à valorização e à utilidade dos recursos vegetais para o equilíbrio ambiental da Terra (PEIXOTO; GUEDES-BRUNI, 2010).

Desse modo, os jardins botânicos, regulamentados no Brasil pela Resolução número 339 de 25 de setembro de 2003 do CONAMA, têm como objetivo "[...] promover a pesquisa, a conservação, a preservação, a educação ambiental e o lazer compatível com a finalidade de difundir o valor multicultural das plantas e sua utilização sustentável" (BRASIL 2003, p. 103). Essa resolução entende um jardim botânico como um espaço protegido, constituído por coleções de plantas vivas reconhecidas pela ciência, documentadas e disponíveis à pesquisa do patrimônio florístico do País, além de proporcionar ao público o acesso à educação, cultura, lazer e consciência ambiental (BRASIL, 2003). Contudo, para Peixoto e Guedes-Bruni (2010), os jardins botânicos no Brasil são, estranhamente, pouco conhecidos.

Para realizarmos atividades pedagógicas nessas áreas, é necessário compreendermos os jardins botânicos além das suas características "naturais", que são simplórias. Calcados por tentar compreender o universo apenas pela ordem, procuramos abdicar da desordem própria aos sistemas, a qual produz não apenas caos, mas inovação e criação. Jardins botânicos são recortes do espaço geográfico, e dificultada é a compreensão deles se suas formas e processos forem engavetados pelas disciplinas, abdicando de tomá-los “[...] a partir da concepção de espaço como um híbrido - híbrido entre sociedade e natureza, entre política, economia e cultura, e entre materialidade e 'idealidade', numa complexa interação tempo-espaço [...]" (HAESBAERT, 2011, p. 79). Nesse contexto, as formas ditas "naturais" 
dos jardins botânicos acabam por ser valorizadas como "coisas em si", através de um modo apenas empírico. As relações terminam por abdicar do contexto e negligenciam as representações que inclusive se escondem por detrás do que está visível aos olhos. Para Santos (2009, p. 41): “[...] a analogia muitas vezes leva a examinar os objetos do exterior, fato que só permite apreender seu aspecto ou sua forma, quando é o conteúdo que em verdade nos permite identificar, individualizar e definir".

Conforme Carlos (2008), na dualidade entre o meio social e o meio natural, que resulta na coisificação das formas, estas terminam por exercer um papel de ocultação. A essência não se revela imediatamente, pois "[...] pode se manifestar em algo que é o seu contrário" (CARLOS, 2008, p. 36). Com efeito, a compreensão dos jardins botânicos como elementos integrantes da sociedade deve começar do postulado de que a sociedade e a natureza se refazem mais entre o movimento e a descontinuidade do que entre a fixação e a continuidade.

Por esse âmbito, um trabalho de campo em jardins botânicos que evoca somente os seus aspectos físicos termina por negligenciar que a “[...] percepção espacial de cada sujeito ou sociedade é resultado, também, das relações afetivas e de referências socioculturais" (CASTROGIOVANNI, 2007, p. 46).

O imprinting (MORIN, 2005) de engavetar o saberes disciplinares, que recebemos na formação acadêmica e que carregamos na trajetória profissional, igualmente se desencadeia quando tomamos como objeto de análise lugares como os jardins botânicos. Rompermos com essa lógica comporta uma mudança de postura árdua, contudo premente, para que se justifique a presença da Geografia como ciência que questiona a realidade. É fundamental que saibamos, seja como for, que "O espaço não se compõe de vazios relacionais, mas é fruto de muitas leituras com infinitas abordagens que dão sentido à textura que o compõe. No momento em que faço geografia em sala de aula, faço relações, e não divisões". (COSTELLA, 2011, p. 109). O cenário que se apresenta é o aprendizado através da interação entre os alunos e os jardins botânicos, almejando compreender essas áreas como elementos complexos da sociedade, construindo uma visão integral da realidade.

\section{Ensinar e (também!) aprender Geografia nos jardins botânicos}

Jardins botânicos, apesar das suas aparências, não são tranquilos. Como elementos da sociedade, constroem não apenas ordem e organização, mas igualmente desordem e intranquilidade. Se quisermos, com efeito, construir conhecimento nessas áreas, precisamos estar ancorados mais na incerteza do que na segurança. De acordo com Morin (2006), a escola, historicamente, apropriou-se de métodos programados e estanques. Vista tal postura como um erro, Morin (2006) sugere que trabalhemos de maneira estratégica, inclusive na construção de uma proposta pedagógica. 
Afinal, estrategicamente, trabalhamos com a incerteza. É o caso das atividades que construímos, que podem entrar num movimento aleatório que impossibilita prever as futuras ações. Para Morin (2005), a ordem é relativa e, portanto, precisamos saber dialogar ao mesmo tempo com a ordem e a desordem. A estratégia, nesse contexto, ancora-se no acaso, mas se prepara para ele. Efetivamente, leva em conta o maior número de certezas, ao passo que tem consciência do enfrentamento que acontece frente às incertezas.

Nesse sentido, propomos aqui estratégias para a elaboração de um trabalho de campo, almejando a construção do conhecimento em Geografia. Contudo, o lastro está nas palavras de Morin (2005, p. 205): “[...] o objetivo do conhecimento não é descobrir o segredo do mundo ou a equação-chave, mas dialogar com o mundo. Portanto, primeira mensagem: 'Trabalhe com a incerteza"'. Vamos munir-nos de uma miríade de certezas, ao mesmo tempo em que sabemos que é necessário trabalhar estrategicamente, ou seja, levando em conta o que é incerto.

\section{Muito além do que o olho vê: A leitura da paisagem}

A leitura da paisagem é uma responsabilidade da Geografia escolar, um dos instrumentos que possibilitam compreender a multidimensionalidade do espaço geográfico. Compreendê-la no seu caráter polissêmico é uma atividade que pressupõe técnica, ancorada num processo metodológico. A paisagem é a materialização de acontecimentos cíclicos e periódicos, alternados por intervalos desiguais, dinamizando as formas e funcionamentos do aspecto visível do espaço.

A fim de diferenciar as unidades paisagísticas, Verdum e Mazzini (2009) propõem quatro critérios para que se realize a leitura de uma unidade paisagística: A forma, produto das dinâmicas e usos sociais, produzindo o aspecto visível; a função, constituída em um processo complexo pelas atividades que foram ou estão sendo realizadas; a estrutura, que contém os valores e as funções da variedade de objetos concebidos em diversos momentos históricos; e o processo: uma ação contínua, produto do tempo geológico e histórico, engendrando diferenciações nas paisagens referentes à dinamicidade dos resultados desse tempo.

As quatro categorias, analisadas em conjunto, ilustram a complexidade com a qual se desenvolve uma paisagem, e a necessidade de ensejar na Escola Básica uma reflexão acerca dos processos responsáveis pelas mudanças e permanências entre os aspectos visíveis do bairro, cidade, Estado. Os estudantes precisam perguntar-se: Por que é assim aqui e lá é diferente? Poderia ser de outra maneira, ou não? Para Cavalcanti (2002), a paisagem problematizada através de uma observação direta ou indireta tem condições de fomentar elementos referentes ao espaço materializado, fornecendo instrumentos para a construção do conhecimento. O Quadro 1 elenca uma proposta de leitura da paisagem, em jardins botânicos, que podem possibilitar uma visão além do aspecto visível deles. 
Quadro 1 - Construindo a análise da paisagem

\begin{tabular}{l} 
ATIVIDADE I - A leitura da paisagem \\
\hline a) Efetue um recorte da paisagem de um lugar de sua escolha. Desenhe-o. \\
b) Qual é a FORMA da sua paisagem? Relembre dois elementos presentes nela que você reconhece. \\
c) Quais são as atividades que estão sendo desenvolvidas na paisagem? Elas representam a FUNÇÃO da unidade paisagística. \\
d) Existem processos de natureza econômica e social na paisagem que você escolheu, ou não? Por quê? Nesse caso, estamos \\
falando da ESTRUTURA de uma unidade paisagística. \\
e) A paisagem também possui o seu TEMPO, geológico e histórico, que indica a influência do passado no presente e as \\
transformações em direção ao futuro. Isso é o PROCESSO ou a DINÂMICA de uma paisagem. Reflita e escreva como estará \\
a paisagem que você observa daqui a 50 anos, imaginando três elementos que nela estarão presentes. \\
ELEMENTO 1: \\
ELEMENTO 2: \\
ELEMENTO 3:
\end{tabular}

Fonte: Elaborado pelos autores.

O estudo da paisagem pode ser um ponto de partida para processos de estranhamento frente às realidades cotidianas: "[...] as coisas percebidas constituem, no fundo, reflexos de coisas não percebidas; isto é, há sempre a epifania de um segredo quando se interpreta a paisagem" (MACIEL, 2001, p. 8). Talvez por isso, para Santos (2009, p. 266 ) “[...] o risco é grande de tomar a aparência pela essência, de privilegiar a paisagem em detrimento da estrutura global que a anima [...]". Às vezes, o que é silenciado pode ser mais relevante que do que está visivelmente presente.

O treinamento do olhar para as configurações espaciais da sociedade não é inato e evoca uma miríade de exercícios na interpretação do mundo. Do contrário, a historicidade das formas e a intencionalidade das funções, processos e estruturas das paisagens podem resultar em uma única observação, numa singular comunicação, inviabilizando a compreensão da polissemia das imagens. Como resultado, desconsiderando a preocupação analítica e o aspecto temporal, "[...] é difícil conceber o espaço tal qual ele é, um objeto real em permanente evolução" (SANTOS, 2009, p. 175). A articulação entre o passado e o presente se manifesta na paisagem, e a compreensão dessa dinâmica aponta para o entendimento do futuro. 
A participação direta nas paisagens dos jardins botânicos é instrumentalizada através do ato de desenhar. O desenho, dizem Oliveira e Portugal (2012), é uma das primeiras manifestações gráficas e estéticas praticadas na história da humanidade, como ferramenta que se torna o produto da comunicação do mundo nos seus aspectos de experiência, memória e imaginação. Kaercher (2007) concorda e incentiva a presença da atividade de se desenhar na escola. Para esse professor, é importante que se dê espaço ao desenho na sala de aula, no sentido de se ultrapassar a visão do que está posto como óbvio: "Não se desenha apenas com as mãos. Usa-se o cérebro, ou seja, ao desenharmos estamos, mais do que desenvolvendo uma habilidade estética, lendo o mundo de forma teórica" (KAERCHER, 2007, p. 31).

O contato imediato com as especificidades espaço-temporais valoriza o ato de desenhar, tornando-o um meio pelo qual a manifestação da ideia e da cultura gráfica ilustra o desenvolvimento da produção da imagem. O desenho é linguagem e representação, que são maneiras de mostrar como os sujeitos estão se apropriando do mundo. Oliveira e Portugal (2012) asseveram que o trabalho com o desenho possibilita novas representações sobre o lugar, analisando espacialmente o mundo e cartografando os percursos que os sujeitos criam e recriam, pois "[...] é através do desenho que a criança começa a registrar os elementos contidos no espaço e a se perceber como sujeito construtor e transformador da paisagem" (OLIVEIRA, PORTUGAL, 2012).

\section{O Código Florestal... Ou a Terra como comunidade de destino}

O Código Florestal protege a biodiversidade. Por que ele causa polêmica, então? Os jardins botânicos, áreas que conservam inúmeras espécies (FUNDAÇÃO ZOOBOTÂNICA DO RIO GRANDE DO SUL, 2004), são meios pelos quais podemos fazer os alunos refletirem acerca da legislação e da sociedade brasileira, tomando como objeto de estudo o Código Florestal Brasileiro. Para Ab'Sáber (2010) a elaboração dessa lei deveria ser realizada por pessoas sensíveis não apenas aos macro e micro biomas da natureza brasileira, mas por cidadãos conscientes da história do país, pautado por desigualdade social e por uma classe privilegiada, que faz parte de uma minoria política que decide os rumos da nação.

O autor propõe uma revisão técnica da lei, visto que esta generaliza de forma perigosa as áreas que estariam suscetíveis a impactos ambientais, e a classifica como agente de uma "liberação excessiva e abusiva" (AB'SÁBER, 2010, p. 332). Ab'Sáber (2010) questiona um dos pilares do modo de produção capitalista, a propriedade privada. Quem de nós nunca pensou ou disse: isto é meu e faço com ele o que quiser? A frase é aplicada às terras passíveis de serem legisladas pelo Código Florestal. O Quadro 2, a seguir, evoca tal comportamento. 
Quadro 2 - Atividade com o Código Florestal em jardins botânicos

\section{ATIVIDADE II - O Código Florestal visto do lado de cá}

a) Imagine-se como o proprietário do jardim botânico no qual você se encontra.

b) Pense e responda, observando a paisagem: Você tem o direito de fazer o que quiser nessa área, mesmo que signifique o fim das características ambientais que estão presentes, ou não? Por quê?

c) Se for significar mais empregos e lucros para a cidade, o jardim botânico deve ser substituído por um shopping, ou não? Por quê?

Fonte: Elaborado pelos autores.

Trabalhar o Código Florestal evoca a transversalidade do conhecimento. O diálogo com a natureza e a sociedade é presente nessa discussão, a qual está relacionada com os problemas inerentes às mudanças climáticas e ambientais de origem antrópica. A compreensão da vida em sociedade e do papel de um cidadão responsável parece que pode ser iniciada a partir do questionamento que levantamos sobre o Código Florestal e a propriedade privada, tomando como local de aplicabilidade áreas como os jardins botânicos. Alguns podem questionar: mas não será óbvia a resposta dos alunos? Eles não estarão conscientizados da importância da manutenção da biodiversidade planetária e da ideia do mundo como uma pátria comum a todos? Queremos questionar e perceber. Uma simples pergunta pode abrir um imaginário de inquietudes e alternativas. Apenas o fato de fazê-los duvidar, alerta-nos que as transformações podem acontecer.

Deveríamos estar atentos aos seus trâmites. Ab’Sáber alerta que é necessária uma bioética com o futuro, visto que "[...] não se faz qualquer projeto de interesse nacional pensando apenas em favorecer de imediato só uma geração do presente [...]" (AB'SÁBER, 2010, p. 335).

Exortar a inquietude nos alunos é transformar a informação em conhecimento, é crescer em autonomia como cidadão.

\section{Um jardim botânico também é parte do mundo... Então ele é arriscado?}

Os espaços públicos nas metrópoles atravessam um processo de transformação. É fundamental refletirmos sobre a concepção dos espaços públicos na contemporaneidade como locais que representam e expressam valores éticos e estéticos, indo além dos seus limites espaciais (SERPA, 2003).

Se jardins botânicos são a expressão da sociedade, eis o questionamento construído: como é estabelecido o relacionamento desses lugares com o espaço geográfico? Será que as palavras de Serpa (2004, p. 26) aplicam-se aos 
jardins botânicos, ou não? “[...] o parque público é um meio de controle social, sobretudo das novas classes médias, destino final das políticas públicas, que, em última instância, procuram multiplicar o consumo e valorizar o solo urbano nos locais onde são aplicadas".

Um processo de reflexão precisa ser estabelecido no que tange aos espaços públicos, como os jardins botânicos. Destarte, a pergunta que estimulamos os alunos a fazer, se determinados lugares de análise deveriam ter entrada gratuita ou não, pode ser retextualizada para outros espaços quaisquer. Perguntar e interagir, além de ser uma prática alicerçada na pesquisa, permite alcançar a práxis defendida por Pontuschka (2004, p. 261): "O contato direto com um local, seja da realidade do aluno, seja de outras realidades, e a reflexão sobre ele permitem que se formem referenciais para entender que o meio não é estático, é dinâmico".

Nesse sentido, os alunos podem aplicar, como os frequentadores dos jardins botânicos, a pergunta semiestruturada proposta no quadro III, que está ancorada nas reflexões sobre a pesquisa qualitativa de Flick (2009). Quando estamos sugerindo aos estudantes que realizem uma pergunta semiestruturada, mostramos a impossibilidade da neutralidade científica: as atitudes, observações e impressões realizadas, em conjunto com uma atmosfera de sentimentos, emoções e tensões, tornam-se dados em si mesmos, passíveis de interpretações e contextualizações (FLICK, 2009).

O Quadro 3 ilustra qual atividade propomos, nesse sentido, para contextualizar os jardins botânicos com os movimentos da sociedade.

\section{Quadro 3 - A sociedade nos jardins botânicos}

\section{ATIVIDADE III - Os alunos no jardim... Investigando no botânico}

Viver é pesquisar. E todos nós somos pesquisadores! Jardins botânicos recebem milhares deles mensalmente. O que eles pensam? Por que estão aqui e não em outros lugares? Compreender o mundo é também se perguntar sobre as pessoas presentes nele, que são atrizes e autoras. A apropriação dos espaços públicos nas cidades pela sua população divide-se com o crescente número de pessoas que veem os shopping centers como as verdadeiras áreas de lazer no século XXI. Por que isso acontece? Será que foi sempre assim? Poderia ser de outra forma, ou não?

a) Você irá encontrar um frequentador do Jardim Botânico e entrevistá-lo.

b) Apresente-se! Diga o seu nome, idade e escola na qual estuda. Deixe claro o que você veio fazer no Jardim Botânico.

c) Não desista no primeiro "não"! Sim, é verdade. Fazer pesquisa é difícil e requer paciência. Não se surpreenda se as pessoas negarem-se a serem entrevistadas. É o direito delas. Não se preocupe: não é pessoal.

d) Pergunte: O Jardim Botânico deve ser um parque aberto ao público, inclusive não sendo cercado, ou não? Por quê?

e) A entrevista foi realizada. Você concorda com as manifestações do entrevistado, ou não? Por que será que o sujeito pensa dessa forma? Justifique sua resposta.

Fonte: Elaborado pelos autores. 
Com a entrevista realizada, os estudantes realizam interpretações em cima das informações que colheram no campo. Ao perguntarmos se eles concordam ou não com a linha de pensamento do entrevistado, e enfatizando a necessidade deles se descentralizarem do seu pensamento e colocaram-se na perspectiva de leitura do outro, estabelecemos uma possibilidade de interação com o meio, avançando no conteúdo. Nesse sentido, as palavras de Castrogiovanni (1996, p. 66) dialogam com a atividade III: "O ensino de Geografia deve oportunizar situações em que o aluno teorize e textualize as suas significações. Chega de ver o mundo em segunda mão"!

Com efeito, o diálogo com os frequentadores dos jardins botânicos engendra processos de conhecimento, os quais estão ancorados no que Piaget (1983) vai chamar de cooperação. Para esse autor, tal dinâmica do pensamento tratase da discussão travada objetivamente, que traz a necessidade da colaboração e da troca de ideias, que se traduz na necessidade de verificação e demonstração. A sociedade, entrementes, age como um alimento que anima e entretém o jogo mental de cada sujeito, o qual "[...] relaciona e representa a reciprocidade entre as diversas atividades" (PIAGET, 1983, p. 166). É necessário que aconteça o intercâmbio entre o sujeito e a vida social, para que haja coerência entre as operações. Sobretudo, [...] é precisamente o intercâmbio constante de pensamentos com os outros que nos permite descentrar-nos dessa forma e nos garante a possibilidade de coordenar interiormente as relações que difundem pontos de vista distintos (PIAGET, 1983, p. 165).

O sentimento de pertencimento aos espaços públicos é uma realidade próxima que a Geografia tem que problematizar, pois se conecta com o estímulo aos princípios democráticos de cidadania que organizam a sociedade. Uma das missões da escola é promover um espaço de cidadania que se reflita na sociedade.

A escola tem condições de ser a porta de entrada para a compreensão das relações planetárias, talvez as transformando: "Se a educação não pode tudo, alguma coisa fundamental a educação pode" (FREIRE, 2011a, p. 110). Somos o que somos, também, pela história do local de onde viemos.

\section{Considerações finais}

Se a sociedade muda, a escola igualmente precisa acompanhar os seus movimentos, se realmente pretende continuar no papel de uma instituição legítima e relevante. Inserido na escola, está o componente curricular Geografia que, nas suas particularidades, também é parte de um todo socioespacial que não pode deixar de acompanhar.

$\mathrm{O}$ artigo apresentado propôs posicionar as aulas de Geografia como momentos nos quais as dúvidas sejam instigadas e a desconfiança, estimulada. Na postura curiosa perante o mundo, os alunos evoluem enquanto sujeitos históricos, acreditando que a sociedade não se posta enquanto entidade estática, mas se transforma na dinamicidade própria do espaço geográfico, que é um verdadeiro campo de forças entrelaçado por relações de poder. 
Por outro lado, ao defendermos a aprendizagem na Geografia escolar através do que os alunos têm de disponível, uma válida alternativa pedagógica é a educação além dos muros da escola, mediada por um trabalho de campo estruturado com instrumentos construídos pelo educador. No momento em que os arredores escolares são compreendidos, os alunos atribuem significados à escola e avançam no entendimento da sociedade. De forma semelhante, o professor que se propõe a construir a sua didática conforme a realidade escolar na qual se inclui ultrapassa a mera cópia e o senso comum e evolui enquanto autor, enxergando sentido na sua prática.

As atividades propostas, de aplicabilidade em jardins botânicos, podem ir além desses e serem aplicadas em outros espaços, com as devidas alterações particulares. Igualmente, como a própria vida, são temporárias e certamente devem passar por mudanças. O que importa, efetivamente, é que na reflexão enquanto educadores autores, o ensino e a aprendizagem tornam-se dinâmicos e muito mais interessantes. Uma alternativa aqui foi apresentada. Ainda existe muito a fazer pela frente. Vamos nos permitir descobrir e... Arriscar!

\section{Referências}

AB'SÁBER, Aziz Nacib. Do Código Florestal para o Código da Biodiversidade. Biota Neotrop, v. 10, n. $4,2010$.

BEAMES, Simon; ROSS, Hamish. Journeys outside the classroom. Journal of Adventure Education and Outdoor Learning, v. 10, n. 2, p. 95-109, Dec. 2010.

BRASIL. Resolução CONAMA nº 339, de 25 de setembro de 2003.

CASTELLAR, Sonia Maria Vanzella et al. Jogos e resolução de problemas para o entendimento do espaço geográfico no ensino de Geografia. In: CALLAI, Helena Copetti (Org.). Educação Geográfica: reflexão e prática. Ijuí: Ed. Unijuí, 2011.

CASTROGIOVANNI, Antonio Carlos. E agora, como fica o ensino da Geografia com a globalização? Cadernos do Aplicação, Porto Alegre: Universidade Federal do Rio Grande do Sul, Colégio de Aplicação, v. 9, n. 1/2, 1996.

CASTROGIOVANNI, Antonio Carlos. Para entender a necessidade de práticas prazerosas no ensino de geografia na pós-modernidade. In: CASTROGIOVANNI, Antonio Carlos; KAERCHER, Nestor André; REGO, Nelson. Geografia: práticas pedagógicas para o ensino médio. Porto Alegre: Artmed, 2007.

CASTROGIOVANNI, Antonio Carlos. Espaço Geográfico escola e os seus arredores - descobertas e aprendizagens. In: CALLAI, Helena Copetti (Org.). Educação Geográfica: reflexão e prática. Ijuí: Ed. Unijuí, 2011.

CALLAI, Helena Copetti. Estudar o lugar para compreender o mundo. In: CASTROGIOVANNI, Antonio Carlos. Ensino de Geografia: práticas e textualizações no cotidiano. Porto Alegre: Mediação, 2009.

CARLOS, Ana Fani Alessandri. A cidade. São Paulo: Contexto, 2008.

CAVALCANTI, Lana. Geografia e práticas de ensino. Goiânia: Alternativa, 2002.

Educação Por Escrito, Porto Alegre, v. 5, n. 2, p. 315-332, jul.-dez. 2014 
CAVALCANTI, Lana. A Geografia Escolar e a Sociedade Brasileira Contemporânea. In: TONINI, Ivaine Maria et al. (Orgs.). O ensino de geografia e suas composições curriculares. Porto Alegre: UFRGS, 2011.

COSTELLA, Roselane Zordan. O significado da construção do conhecimento geográfico gerado por vivências e por representações espaciais. Tese (Doutorado em Geografia) - Instituto de Geociências, UFRGS, Porto Alegre, 2008.

COSTELLA, Roselane Zordan. Em que momento um aluno aprende geografia. In: CASTROGIOVANNI, Antonio Carlos; KAERCHER, Nestor André; REGO, Nelson. Geografia: práticas pedagógicas para o ensino médio. Porto Alegre: Penso, 2011. v. 2.

FLICK, Uwe. Introdução à pesquisa qualitativa. Porto Alegre: Artmed, 2009.

FRANCO, Sérgio Roberto Kieling. Piaget e a Dialética. In: BECKER, Fernando; FRANCO, Sérgio (Orgs.). Revisitando Piaget. Porto Alegre: Mediação, 1998.

FREINET, Célestin. Pedagogia do bom senso. São Paulo: Martins Fontes, 1991.

FREIRE, Paulo. Pedagogia da autonomia: saberes necessários à prática educativa. 43. ed. São Paulo: Paz e Terra, $2011 \mathrm{a}$.

FREIRE, Paulo. Pedagogia do oprimido. 50. ed. Rio de Janeiro: Paz e Terra, 2011b.

FUNDAÇÃO ZOOBOTÂNICA DO RIO GRANDE SUL. Jardim Botânico de Porto Alegre. Plano Diretor do Jardim Botânico de Porto Alegre. Porto Alegre: 2004.

HAESBAERT, Rogério. O mito da desterritorialização: do "fim dos territórios" à multiterritorialidade. Rio de Janeiro: Bertrand Brasil, 2011.

KAERCHER, Nestor André. Ler e escrever a geografia para dizer a sua palavra e construir o seu espaço. In: NEVES, Conceição Bitencourt; SOUZA, Jusamara Vieira; SCHAFFER, Neiva Otero; GUEDES; Paulo Coimbra; KLUSENER, Renita. Ler e escrever: compromisso de todas as áreas. Porto Alegre: UFRGS, 2003.

KAERCHER, Nestor André. Práticas geográficas para lerpensar o mundo, converentendersar com o outro e entenderscobrir a si mesmo. In: CASTROGIOVANNI, Antonio Carlos; KAERCHER, Nestor André; REGO, Nelson. Geografia: Práticas pedagógicas para o ensino médio. Porto Alegre: Artmed, 2007.

MACIEL, Caio Augusto Amorim. Morfologia da paisagem e imaginário geográfico: uma encruzilhada onto-gnoseológica. Revista Geographia, Niterói, Universidade Federal Fluminense, a. 3, n. 6, p. 1-12, 2001.

MAURICE-NAVILle, Danielle; MONTANGerO, Jacques. Piaget ou a inteligência em evolução. Porto Alegre: ArtMed, 1998.

MORIN, Edgar. Ciência com Consciência. Rio de Janeiro: Bertrand Brasil, 2005.

MORIN, Edgar. A cabeça bem feita: repensar a reforma, reformar o pensamento. Rio de Janeiro: Bertrand Brasil, 2006.

OLIVEIRA, Simone Santos de; PORTUGAL, Jussara Fraga. O ensino da Geo(Carto)grafia: práticas com o desenho numa proposta interdisciplinar. In: PORTUGAL, Jussara Fraga; CHAIGAR, Vânia Alves Martins. (Org.). Cinema, literatura e outras linguagens no ensino de Geografia. Curitiba: CRV, 2012, v. 01, p. 185-212.

PEIXOTO, Ariane Luna; GUEDES-BRUNI, Rejan R. Jardins Botânicos. Ciência e Cultura, São Paulo, v. 62, n. 1, 2010. Disponível em: <http://www.cienciaecultura.bus.br>. Acesso em: 22 dez. 2012. 
PIAGET, Jean. A epistemologia genética. São Paulo: Abril Cultural, 1978.

PIAGET, Jean. Psicologia da inteligência. Rio de Janeiro: Jorge Zahar, 1983.

PIAGET, Jean. O nascimento da inteligência na criança. 4. ed. Rio de Janeiro: LTC, 2008.

PONTUSCHKA, Nídia Nacib. O conceito de estudo do meio transforma-se... em tempos diferentes, em escolas diferentes, com professores diferentes. In: VESENTINI, José William (Org.). O ensino de Geografia no século XXI. Campinas: Papirus, 2004.

PONTUSCHKA, Nídia Nacib et al. Para ensinar e aprender Geografia. São Paulo: Cortez, 2009.

SABINO, Fernando. O encontro marcado. Rio de Janeiro: Record, 2008.

SANTOS, Milton. A Natureza do Espaço: técnica e tempo, razão e emoção. 4. ed. São Paulo: Ed. da USP, 2009.

SANTOS, Milton. Por uma Geografia Nova: da crítica da Geografia a uma Geografia crítica. 6. ed. São Paulo: Ed. da USP, 2012.

SCHAFFER, Neiva Otero. Ler a paisagem, o mapa, o livro... Escrever nas linguagens da geografia. In: NEVES, Conceição Bitencourt; SOUZA, Jusamara Vieira; SCHAFFER, Neiva Otero; GUEDES; Paulo Coimbra; KLUSENER, Renita. Ler e escrever: compromisso de todas as áreas. Porto Alegre: Ed. da UFRGS, 2003.

SEGAWA, Hugo. Ao amor do público: jardins no Brasil. São Paulo: Studio Nobel/FAPESP, 1996.

SERPA, Ângelo. Parque público e valorização imobiliária nas cidades contemporâneas: tendências recentes na França e no Brasil. In: ENCONTRO NACIONAL DA ANPUR (Associação Nacional de Pós-Graduação em Planejamento Urbano e Regional), X., 2003, Belo Horizonte. CD-ROM - X Encontro Nacional da ANPUR: Encruzilhadas do Planejamento - Repensando Teorias e Práticas. Belo Horizonte: ANPUR/UFMG, 2003. v. 1. p. 1-15.

SERPA, Ângelo. Espaço público e acessibilidade: notas para uma abordagem geográfica. GEOUSP - Espaço e Tempo, São Paulo, n. 15, p. 21-37, 2004.

VERDUM, Roberto; MAZZINI, Luis Fernando Fontoura. Temáticas rurais: do local ao regional. In: Planejamento e gestão para o desenvolvimento rural da SEAD/UFRGS. Porto Alegre: Ed. da UFRGS, 2009.

VESENTINI, José William. Realidades e perspectivas do ensino de Geografia no Brasil. In: VESENTINI, José William (Org.). O ensino de Geografia no século XXI. Campinas: Papirus, 2004.

Endereço para correspondência:

Bruno Nunes Batista

Colégio Tiradentes da Brigada Militar

Av. Aparício Borges, 2001 - Partenon

90570-680 Porto Alegre, RS, Brasil

E-mail: <brunonunes.86@hotmail.com>

Recebido em: jun./2014

Aceito em: ago./2014 